\title{
Chapter 7 \\ Coping with Covid-19: Forging Creative \\ Pathways to Support Educational \\ Continuity Amidst the Pandemic
}

\author{
Vidya Yeravdekar and Nidhi Piplani Kapur
}

\begin{abstract}
The pandemic has forced all educational institutions to grapple with challenges. Throughout this time Symbiosis International University (SIU) in India has been proactive in leading change not only at the university but also in K-12 schools. While the university transitioned to virtual teaching and learning, a methodical approach was laid out in assisting its eight elementary and senior secondary schools in both urban and rural areas, through the Symbiosis Schools Central Directorate (SSCD), to adapt to the needs of a public health crisis. While connectivity challenges continue to haunt schools, especially in rural areas, training and capacity building of K-12 teachers and administrators by university professors and experts has been a saving grace in navigating the pandemic.

The focus of this case is understanding the parallels and the partnership between SIU and its K-12 schools. It reflects a bottom-up approach in dealing with the pandemic where Symbiosis Society, the non-profit organization that has established the schools as well as the University, invested in teacher capacity building at its elementary and secondary schools through its Symbiosis Schools Central Directorate (SSCD) in both rural and urban areas to ensure continuity of teaching and learning while adapting to this new normal. The investment in teacher capacity building has enabled the leadership to address the emerging circumstances, stimulate momentum to create or demand needed change at their institutions, inspire peer learning, and foster innovation in strategy and practice for the greater benefit of its stakeholders including students and parents.

This case study reflects on SIU experiences in dealing with the dynamic circumstances such as training and capacity building with respect to supporting teachers in developing skills to adapt their content to virtual mode, blended learning, and inte-
\end{abstract}

A Blended Approach to Advancing Teaching and Learning: A Collaborative Effort of Symbiosis Schools Central Directorate and Symbiosis International University, India.

V. Yeravdekar · N. P. Kapur $(\bowtie)$

Symbiosis International University, Pune, India

e-mail: head_sces@scie.ac.in 
grating Collaborative Online International Learning (COIL) into the curriculum. In addition, SIU had to counsel students and parents to adapt to this new way of learning. SIU's experience encompasses a coordinated approach of working with internal and external stakeholders to develop a response to the crisis, short-to-medium-term strategic planning in the face of uncertainty, exploring technology solutions, partnership management, and effective communication processes with its stakeholders. Special emphasis has been put on ensuring the mental and physical wellbeing of the learner, constant communication and guidance to parents, and virtual activities to promote community engagement to mitigate the loss of physical social interactions at this crucial time.

\subsection{Introduction}

When our Honorable Prime Minister Shri Narendra Modi announced the sudden lockdown in India on March 25, 2020, it brought about abrupt disruptions to the second fastest growing economy in the world. With 247 million children enrolled in elementary and secondary schools in India left in an educational limbo due to this public health crisis, immediately questions arose about the educational implications of such disruption for a young economy.

Every sector has been hit significantly, because of the social distancing measures. In a developing country that is fast growing in terms of both economy and population, the education systems have been particularly rocked because of the large number of students they serve. While many schools and higher education institutions (HEIs) have adopted a reactive approach to respond to the crisis, Symbiosis International University in India has been proactive in leading the change their students and campuses needed. Symbiosis, a large family of K-12 schools, and HEIs navigated the situation by focusing on a "blended/hybrid approach" in teaching and learning. Blended/hybrid learning is defined as a combination of synchronous and asynchronous forms of delivery. Synchronous learning is online or distance education that happens in real time, whereas asynchronous learning occurs through online channels without real-time interaction.

While the university transitioned to virtual teaching and learning, a methodical approach was laid out in how to assist its elementary and senior secondary schools spread across rural and urban areas of the country. It has not been an easy process especially due to low bandwidth and connectivity impacting teaching and learning in its schools in rural areas. On the other hand, training and capacity building of schoolteachers and administrators by university professors and experts have been a saving grace in this pandemic. 


\subsection{The Journey of Symbiosis}

Symbiosis has a unique history of being the only institution in India that was created as a "home away from home" for international students. Symbiosis Society, a trust that encompasses both the University and the K-12 schools, was established in 1971 to "promote international understanding through quality education." Symbiosis developed its motto to be "Vasudhaiva Kutumbakam," which translates to "the world is one family." With its foundation based on forging a symbiotic relationship between foreign and Indian students, its philosophy is drawn from a blend of Eastern wisdom and Western dynamism. To realize its vision of "promoting international understanding through quality education," SIU has kept internationalization as a very strong focus in all its activities and believes that it is much needed in today's globalized world. Coincidentally, Symbiosis celebrates its golden jubilee this year. Today, Symbiosis, a private entity, has over 40,000 students from all States of India and over 85 countries across the globe studying in 70 of its institutions spread across Pune, Nashik, Nagpur, Noida, Bangalore, and Hyderabad.

\subsection{SIU's Support for K-12 Schools during the Pandemic}

In 2015, Symbiosis Society created Symbiosis Schools Central Directorate (SSCD) to ensure equity, excellence, and consistency across all Symbiosis Schools. SSCD is the central office entrusted to make these schools the most reputable schools. SSCD ensures that SIU collaborates in the quality enhancement of the schools as required. The human and material resources of the university are utilized optimally to strengthen the elementary and secondary education at the various schools.

SIU contributes to both the rural and urban schools. These efforts and interventions are not new, but the present pandemic has reinstated the efforts and highlighted on some focus areas, namely, the use of virtual learning. Since the lockdown, SIU has increased its investment of resources and finances in these K-12 schools. Investments have been made in capacity building of schoolteachers in adapting their content to the online environment, making content engaging for students, and ensuring achievement of outcomes through blended learning. A special training on Collaborative Online International Learning (COIL) has been also taking place for its urban schools.

The scale of these efforts has been immense in urban areas, but unfortunately rural schools have not been able to achieve their target. The 23 schools adopted in the Lavale villages, neighboring SIU, are also facing similar issues as they are crippled due to poor access to Internet and bandwidth issues. Also, since more than $50 \%$ of the Lavale villages schools are elementary, they are affected by the regulations and restrictions the government imposed on virtual learning for young students. An alternative solution of learning through television and community radio is being 
Table 7.1 Schools managed by SSCD

\begin{tabular}{l|l}
\hline Name & $\begin{array}{l}\text { Number of students impacted by } \\
\text { these efforts }\end{array}$ \\
\hline Rural schools & 194 \\
\hline Symbiosis school, Harali & 1228 \\
\hline 23 schools adopted in Lavale Village & $\mathbf{1 4 2 2}$ \\
\hline Total (rural) & 433 \\
\hline Urban schools & 350 \\
\hline Symbi stars, Pune & 268 \\
\hline Symbiosis kindergarten, Nashik & 1894 \\
\hline $\begin{array}{l}\text { Pune police public school kindergarten, Shivajinagar, } \\
\text { Pune }\end{array}$ & 710 \\
\hline $\begin{array}{l}\text { Symbiosis primary and secondary school, Prabhat road, } \\
\text { Pune }\end{array}$ & 1368 \\
\hline Symbiosis international school, Viman Nagar, Pune & 1152 \\
\hline Symbiosis school, Nashik & $\mathbf{6 1 7 5}$ \\
\hline $\begin{array}{l}\text { Pune police public school (primary and secondary), } \\
\text { Shivajinagar, Pune }\end{array}$ &
\end{tabular}

explored for students studying in rural areas, which will be the first time this strategy is attempted for these schools (Table 7.1).

\subsection{Key Methodology during the Pandemic}

Figure 7.1 summarizes how the Symbiosis Society, operating through the Central School Directorate, integrated efforts to mitigate the educational impact of the pandemic in the schools and SIU, through four key areas of action and partnership.

\subsubsection{Addressing Emerging Concerns}

The SSCD, an umbrella institution for schools under the Symbiosis Society, coordinates these developmental efforts with SIU through the Symbiosis Teaching Learning Resource Centre (STLRC). SIU conducts workshops and training programs for faculty and schoolteachers to promote capacity building, technological solutions for e-learning, and resource persons. These resource persons are faculty members from SIU who are involved in handholding and training schoolteachers. The pace of these efforts has picked up due to the emergency of moving to virtual learning. Typically, STLRC (SIU) earmarks a special budget of approximately 5\% for development of schools which was increased to $10 \%$ this year due to the pandemic. A budget of USD 19000 (approx.) equivalent to INR 13,385,600 has been 

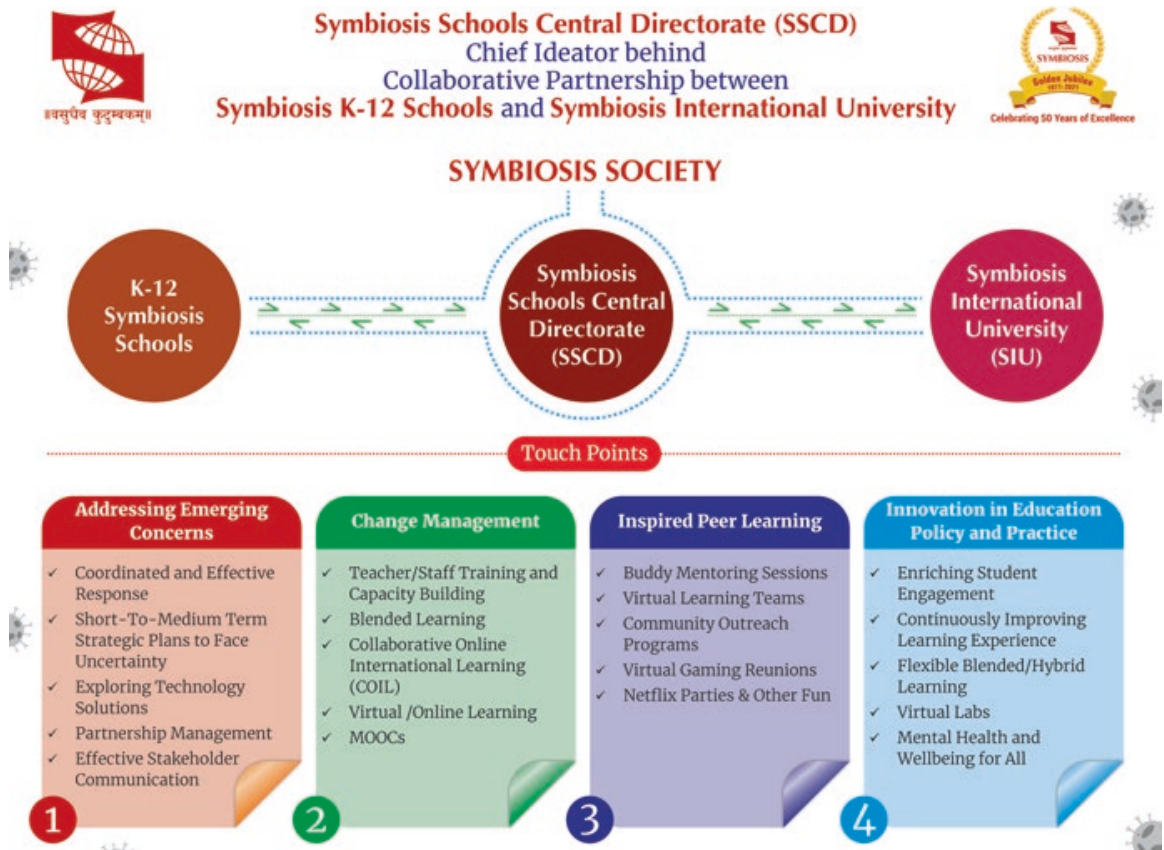

Fig. 7.1 Symbiosis Schools Central Directorate integrates education response during the pandemic in K-12 schools and the university

allocated. A large part of this budget is being used to invest in technology solutions like Padlet, Zoom, and Microsoft teams. Open-source learning management system software Moodle, Canvas, intranet websites, e-learning courses, Curiosity software, digital library, NPTEL online lecture series, and online tutorials, webinars, and virtual laboratories are also being used for conducting blended learning.

In rural schools, a part of this budget was spent months before the lockdown to install solar panels, undertake digital literacy and learning sessions for teachers, students, and parents, invest in sport equipment, construction work, and a special provision for scholarships for 11 female students.

In urban schools, SIU set up a special lab as part of India's "Content and Language Integrated Learning (CLIL)" project, a program for schoolteachers and students co-funded by the European Union's Erasmus+ program. This lab embraced the multilingual culture of India and helped students ease into classrooms that are predominantly monolingual. The education through these labs was shifted to the virtual environment to continue support, with a special focus on the vernacular language of Marathi. An investment of approximately USD 24000 equivalent to INR 17.5 lakhs was done at our Symbiosis School, Prabhat Road.

The University's efforts to support these initiatives did not start at the beginning of the pandemic, but rather built on already established goals and programming. It 
is true, however, that the urgency to fuel these efforts was greatly increased after the sudden lockdown resulting from the pandemic.

The efforts reinstate the institution's mission statements of contributing toward knowledge generation and dissemination, thereby inculcating the spirit of "Vasudhaiva Kutumbakam" (the world is one family). This has led to an "inclusive" approach to teaching and learning both at the K-12 schools and SIU, where technology has become an enabler. Through STLRC, the SSCD ensures that faculty members are trained in the use of modern innovative practices and thus able to execute the methods well. The SIU professors have mentored and trained schoolteachers to bring in ICT and use technology for their students' and their own benefits without compromising on the learning outcomes.

In addition to ICT, school staff and leadership have increased their skillsets in softer areas which focus on non-technical skills. This primarily aims at developing ability of teachers to respond to parents and other stakeholders in the pandemic. This was done through dedicated training of schoolteachers by the university professors which also included specific sessions that involved our Symbiosis Centre for Emotional Wellbeing. The schoolteachers have therefore been able to develop a coordinated approach to communicate with internal and external stakeholders in response to emerging circumstances, dynamic short-to-medium-term strategic planning such as adapting to changes day-by-day, and partnership management for various projects.

These changes have impacted the overall quality of the learning experience. For SIU, this has also resulted in a slow but steady increase in the number of research papers and virtual presentations in International Conferences, participation in e-seminars, achievements at intercollegiate competitions, and participation in national and inter-varsity activities, despite the gloomy period.

\subsubsection{Change Management}

The Symbiosis Society has provided administrative and financial support to all initiatives between the schools and university. There has been direct support from the leadership which includes the Principal Director of Symbiosis Society, Pro Chancellor and Vice Chancellor of SIU, and Board of Management (BOM). This has enabled university professors to seamlessly empower schoolteachers with technological support and soft skills, especially through a difficult time imposed by the pandemic.

The Covid-19 pandemic suddenly brought to the forefront the immediate need of shifting the teaching and learning process to the online mode. Though the initial reaction may have been passive in certain cases, it did not take long before teachers rose to the occasion and transitioned from a reactive to a proactive approach. This movement resulted in blended learning as an alternative to face-to-face learning. The schools have now shifted to the blended mode of curriculum. This step has been taken in consideration of the uncertainty that schools may or may not reopen due to 
the ongoing crisis. In case the schools are forced to remain shut even in 2021 due to deadly second wave of the Covid-19 pandemic, the teachers have planned the curriculum such that there is a blend of synchronous and asynchronous teaching using the online learning platforms. The urban schoolteachers are also being trained on integrating Collaborative Online International Learning (COIL) into the curriculum, creating virtual programs, MOOCs, etc. These efforts were initiated since this was the best way to reach the learners in a way that does not disrupt the learning continuity. A total of 342 urban and nine rural schoolteachers were trained.

COIL, also referred to as globally networked learning and virtual exchange, is a new teaching.

and learning paradigm that promotes the development of intercultural competence across.

shared multicultural learning environments. Using Internet-based tools and.

innovative online pedagogies, COIL fosters meaningful exchanges between university-level.

teachers and students with peers in geographically distant locations and linguistically different backgrounds. This is a bi-directional methodology involving teachers to co-create the module. Delivery happens real time where students from both parts of the world learn from each other's reflection. COIL has been particularly useful for our urban senior secondary and IB school to bridge the learning gap experienced due to the limitation on physical mobility imposed by the pandemic.

The university initiated the first of its kind in India, "E-Academies on Internationalization." Through the faculty E-Academies, the central international office of the university sourced resource persons from different parts of the world who conducted half day workshops that were hands-on and cutting edge in different topics. The trainings focused on advancing internationalization at home, both for our schools and university. The trainings were centered around topics that helped teachers design their curriculum and instruction, understand, and use COIL methodology in teaching and learning and integrate climate action in the curricula. Some of the senior secondary school teachers from our schools were trained on this aspect.

\subsubsection{Inspire Peer Learning}

In India, unlike other countries where education is state funded, most schools are privately managed. The private schools have been very proactive; in addition, the teachers have been rising to the occasion to give their best efforts during this sudden shift in teaching and learning. However, the major constraints in these efforts have been the poor connectivity and low bandwidth in many areas especially the remote areas and rural sector. Reaching out to the urban students was not a big challenge since most of them had the necessary hardware and software required for online teaching and learning. Moreover, the urban students as well as their parents are comparatively more technologically savvy than their rural counterparts. 
Parental involvement had a major role to play during this teaching and learning shift, and their presence around the children during the initial phases has been a big advantage in the process. The parent community was initially reluctant to this new change due to the increased screen time and competing pressures of their own jobs and home commitments. However, after getting oriented parents have now become an active participant in this Covid-19 phase. Schools regularly interact with the parents so that the children get the necessary support and required supervision. Emphasis has been laid on inspiring peer learning through small virtual teams, simulations in virtual labs, buddy mentoring, etc. A special focus has been given to ensure mental and physical wellbeing for both students and parents. Informal virtual morning/coffee sessions with parents, meditation mornings, gaming reunions, Netflix evenings, and other social events are planned to ensure the continuity in nurturing of social skills. A counsellor is available for virtual meetings for both students and parents to deal with the ongoing stress in this situation. Community engagement with activities like create and donate a mask were carried out to help the underprivileged. Care, agility, and action have been the cornerstones in navigating through this challenging and dynamic times.

\subsubsection{Nurture Innovation in Policy and Practice}

There has been a systematic monitoring in place to ensure that the efforts are leading in the right direction. The office of Symbiosis Schools Central Directorate (SSCD) is actively involved in monitoring all these efforts. SSCD conducts regular meetings with the heads of schools and understands the processes involved in the implementation of online classes. The curriculum and instruction planning, i.e., lesson plans, are submitted by the schools to the SSCD office after which the quality aspects are deliberated on before they are approved. Moreover, SSCD office bearers randomly go online while lessons are being conducted to see if the implementation is happening in accordance with the planning. Feedback gathered from students is shared with teachers as well as heads of the respective schools. SIU professors are handholding and mentoring schoolteachers who are in the nascent stage and continuing their efforts in improving teaching and learning through technology.

In addition to these self-monitoring practices, SSCD is open to constructive criticism from the parent community. Parents very often send mail to SSCD sharing their concerns, difficulties, or the things they appreciate. Each message receives a response and further action is also taken by SSCD, if necessary. SSCD strives to give the best educational experience to their learners by monitoring the complete system, evaluating it, and taking the necessary steps to improve and grow.

The efforts have achieved positive results so far, and both the teachers and students are excited and looking forward to the next academic year of online learning. In India, the new academic year begins in the month of June. The teachers are better prepared after a very short summer break especially now that they have been able to understand their strengths and limitations and are working to improve on their 
weaknesses. The beginning of online teaching and learning was a very sudden transition, and most of the teachers were caught unprepared. They did not get sufficient time to prepare their best lessons and so their instruction may have been compromised in certain areas. Nevertheless, teachers are a strong community and should be commended for their efforts to increase their skills and bring out the best of themselves and their students. In the month of June, through the mentoring and training received from SIU professors, they are much better prepared and much more confident after their learning experience in April and May 2020. The teachers, the heads of school, and the management have reviewed the previous lessons, and their feedback has enriched and motivated the teachers to learn from their mistakes and do better.

The efforts are now moving in a concerted direction to build on blended learning. Approaching challenges day-by-day has made teachers and staff resilient to change, and they are now better able to cope and adapt to the emerging circumstances, something that was a major difficulty before.

\subsection{The Hits and Misses}

The sudden need to transfer the teaching and learning mode to the online environment has made the educator community come face to face with some unexpected results.

\section{Positive:}

- Parents have been active partners in the efforts taken by the schools to facilitate learning. Never before have the parents been so involved in the classroom activities.

- Teachers have become more accountable for what they are teaching since anyone can be a virtual participant in the classroom activities.

- The teaching and learning community have accelerated their technological preparation to face the virtual classroom with greater ease.

- Students are getting a multimodal experience which may have been missing in many of the conventional classrooms. Teachers are teaching the way students have always preferred to learn.

- Since the parental expectations from the schools have increased multifold, it has prompted the teachers and schools to take proactive steps in their efforts to improve the quality of delivery and communication.

\section{Negative:}

- The biggest challenge that we have realized is the divide between the urban and rural community in terms of access to technology. If these efforts need to be sustained in the future, it shall require proper government intervention in various phases of the rural sector. It may be in the form of infrastructural support to strengthen Direct-to-Home DTH broadcasting service, community radio, etc. so that the accessibility is improved. 
- Because the students are not interacting in schools, this has also led them to be deprived of opportunities to practice some key social skills. Since learning is happening in the isolation of their respective homes, learners are away from their peer groups resulting in lack of peer-to-peer learning, cooperation, communication, empathy, etc.

- This new teaching and learning modality has led to more screen time, leading to digital fatigue for students. This was something we hoped to avoid, but with no better option, children are spending a lot more time in front of their gadgets.

- Children are missing out on fun-filled activities such as physical education, arts, and crafts, etc. It is not natural for the children to learn in the confines of the four walls. In the current situation they are being kept away from playgrounds which act as an important learning center in the life of a child.

- Due to the increased parental expectations, this would pose a challenge to the school and staff even after the blended mode of curriculum transaction has begun.

\subsection{Beyond Imagination: What Did Not Work}

One of the biggest shortcomings of these efforts has been our inability to reach out to the rural students the way their urban counterparts have been reached. Since the complete shift in the process has been dependent on technological support, it has turned out to be the biggest bottleneck. The poor connectivity and lower bandwidth have resulted in the lack of accessibility.

On the other hand, though accessibility has not been a problem with the urban learners, there have been concerns shared by anxious parents regarding the amount of time students are now spending on a screen.

Apart from these specific issues, the biggest failure of this approach has been the lack of social development of students. They are missing out on face-to-face peer learning which is an important developmental aspect of their school-age years. The social isolation has also resulted in the reduced opportunity to learn and practice social skills.

\subsection{A Revolution that Is Not}

There could be no better time for the transition from face-to-face teaching to online teaching and learning than now. If we were to take advantage of this opportunity, we could shift to a blended mode of teaching and learning in the future in a way that expands opportunities for all. However, this pandemic had not given sufficient time to the schools to be prepared for this change, although it has alerted us to the importance of being better prepared moving forward. Schools will now create a stronger system and invest in different hardware and software to create school level parallels of such organizations as Coursera, other MOOCs, etc. Moreover, SSCD will take 
systematic steps to orient the schoolteachers on better delivery using these mediums through different professional development programs. The higher education faculty members of SIU and students from the university pursuing IT and Computer Studies shall also be roped in to give the necessary training to the school staff.

The coronavirus pandemic has brought to the forefront the realization of the need to enhance the use of existing resources and approaching new ways to teaching and learning. It has been less of a revolution of the system but more [a shift] of mindsets of the thousands of students and parents who are culturally diverse but united by the thread of face-to-face education. This pandemic does not bring a revolution, but rather an evolution of what we already had but did not recognize. Blended learning is now going to be the new reality, but in a country like India, it is still going to be a luxury available mostly to urban communities unless policy makers step in. Systemic efforts are required to ensure last mile connectivity of basic Internet access in rural areas for those students to benefit without any discontinuity in their learning, a challenge that is beyond the scope of the school or university leadership.

It is now time to value the indigenous knowledge and foster collaborative efforts that connect people to their territory. Social/physical distancing will be the norm till the younger population is inoculated and we champion herd immunity. While dealing with and emerging out of this pandemic, what is going to remain with us is how these networks support, mentor, and evolve in the process.

\section{References}

Chen, I. (2011). Instructional design methodologies. In Information Resource Management Association (Ed.), Instructional design: Concepts, methodologies, tools, and applications (Vol. 1, pp. 80-94). IGI Global. https://doi.org/10.4018/978-1-60960-503-2.ch108

Karen S. C. Thomas (2019). Handbook of research on critical thinking and teacher education pedagogy (pp. 255-276).

Hayden Wimmer, Loreen Powell, Lawrence Kilgus and Christina Force (2017). International journal of online pedagogy and course design (pp. 1-19).

Jamie Mahoney, Carol A. Hall (2020). Exploring online learning through synchronous and asynchronous instructional methods (pp. 52-76).

Middlebrook, G. (2015). Synchronous and asynchronous modalities. In B. L. Hewett \& D. P. K. Eric (Eds.), Foundational practices in online writing instruction (pp. 129-148). Perspectives on Writing, The WAC Clearinghouse and Parlor Press.

SUNY COIL Centre. Faculty Guide for Collaborative Online International Learning Course Development. http://www.ufic.ufl.edu/UAP/Forms/COIL_guide.pdf (accessed July 30, 2020).

Dr. Vidya Yeravdekar is the Pro-Chancellor, SIU, and the Principal Director of Symbiosis Society, which encompasses the Symbiosis schools, College of Arts \& Commerce. Dr. Vidya holds a Postgraduate Degree in Medicine, a degree in Law, and Ph.D. in "Internationalization of Higher Education in India." She has been a member of the University Grants Commission for two terms, Central Advisory Board of Education, India Brand Equity Foundation Trust, ICCR, and many other organizations. She is currently the Chairperson of the FICCI Committee on Higher Education. Dr. Vidya has been ranked one of India's top 25 Powerful Women by Fame India Magazine and has also been recently awarded "Exemplary leader in internationalization of Indian education" at the 30th annual EAIE conference in Geneva, Switzerland. 
Prof. Nidhi Piplani Kapur is the Head of Symbiosis Centre for European Studies (SCES), Symbiosis International University (SIU) in Pune, Maharashtra, India. Prof. Nidhi was also the youngest and only Indian elected to General Council, the highest governing body at European Association for International Education (EAIE), located in the Netherlands. At Symbiosis, Prof. Nidhi set up the Symbiosis Centre for European Studies (SCES) which is an umbrella support system for all academic/scholarly/generic activities of SIU Institutes with European nations/institutes. It facilitates more meaningful, research-based, and strategic partnerships and projects with European counterparts. She is also a professor in Economics and Strategy. An alumna of University of Delhi, she specializes in Economics at the undergraduate and postgraduate level.

Open Access This chapter is licensed under the terms of the Creative Commons Attribution 4.0 International License (http://creativecommons.org/licenses/by/4.0/), which permits use, sharing, adaptation, distribution and reproduction in any medium or format, as long as you give appropriate credit to the original author(s) and the source, provide a link to the Creative Commons license and indicate if changes were made.

The images or other third party material in this chapter are included in the chapter's Creative Commons license, unless indicated otherwise in a credit line to the material. If material is not included in the chapter's Creative Commons license and your intended use is not permitted by statutory regulation or exceeds the permitted use, you will need to obtain permission directly from the copyright holder. 